\title{
UNA NOTA SOBRE NUEVAS APORTACIONES AL PENSAMIENTO ECONOMICO ESPAÑOL EN EL SIGLO XX
}

\author{
JUAN VELARDE FUERTES \\ Universidad Complutense de Madrid
}

Recientemente he participado en la dirección de dos tesis doctorales y he estado en el Tribunal de una tercera. Todas se refieren a cuestiones de nuestro pensamiento económico. Afectan a un miembro de la generación del 98 de economistas, Francisco Bernis Madazo, y a dos discípulos de Flores de Lemus situados en la historia de nuestra ciencia en dos momentos muy dispares. El primero, Luis Olariaga Pujana, formó parte del grupo inicial de estudiosos que constituyeron el Seminario inicial lleno de talante germano de Flores, junto, sobre todo -luego volveré acerca de esto-, a Viñuales, Rodríguez Mata, Gay, Carande, Alvarez Cienfuegos y Gabriel Franco. El segundo, Valentín Andrés Alvarez, apareció en la órbita de Flores de Lemus en los momentos finales de la labor de éste como gran escolarca de la ciencia económica española. Conocidas de todos son las dolorosas circunstancias que rodean los últimos días de las relaciones con el maestro de los discípulos de Flores. Uno de ellos, su nombre no hace al caso y queda para los que hacen bistoria chacal si es que lo localizan, tiene la vacilación de Pedro. Niega al maestro. Otros andan dispersos. Pero algunos permanecen firmes y fieles. El fue, ante el asombro de Flores, como ya he relatado en otra parte y volveré a puntualizar hoy, que lo consideraba discípulo muy marginal -y en algún sentido, lo era-, quien se niega a negar, y acude asiduamente a la casa del maestro hasta sus últimos momentos, con, al menos, José María Naharro y José Antonio Piera Labra. Son tres personajes señeros - Bernis, Olariaga y Valentín Andrés Alvarez-, con aportaciones de muy dispar signo, pero fundamentales para nuestra economía. A los tres los estudié inicialmente en tres trabajos que andan por ahí. Los tres han recibido ahora tan cuidadosa atención que su vida y obra han de ser, a la fuerza, recreadas de este año en adelante.

A Bernis corresponde la tesis doctoral de José Miguel Fernández Pérez, Francisco Bernis en la bistoria del pensamiento económico español del primer tercio del siglo $X X$. Departamento de Estructura Económica y Economía Industrial (Universidad Complutense de Madrid), Madrid, octubre 1987, tres volúmenes, con un total de 1.392 páginas. 
De Olariaga se ocupa la titulada Problemas geopolticos, sociales y económicos en la obra periodística del profesor Olariaga, de la que es autora M. ${ }^{a}$ Carmen Pérez de Armiñán y García-Fresca, Universidad Complutense de Madrid, Facultad de Geografía e Historia, Departamento de Geografía Humana, año 1986/87, 674 páginas.

De Valentín Andrés Alvarez trata la de Alfonso Sánchez Hormigo, Valentin Andrés Alvarez y su aportación a la Economía Aplicada en España, Universidad de Zaragoza, Facultad de Derecho, Zaragoza, septiembre 1987. 534 páginas.

El trabajo del profesor Fernández Pérez es la culminación de una indagación sobre Bernis que dura ya muchos años. Sus primeros pasos se remontan al curso 1978-79. Por consejo mío, eliminó parte notable de los materiales que tenía acumulados -en particular, los que se referían a un famoso dictamen sobre el Banco Agrario- porque hubieran hecho de este trabajo una tesis descomunal y de redacción demasiado dilatada en el tiempo. Por eso, en el fondo, se trata, según el autor, de presentar «un análisis general de la trayectoria vital, intelectual y profesional de este economista. $\mathrm{O}$, dicho de otra manera, a la vez que se traza un esbozo biográfico de Bernis se quiere poner de relieve las circunstancias de todo tipo que rodean la elaboración de su obra - y que, en gran medida, ayudan a explicar las limitaciones de la misma-, lo que dicha obra supone de aportación al conocimiento de la economía española de la época y, por último, los aspectos más destacados de su actuación profesional como técnico al servicio de la banca privada española».

A los tres capítulos que constituyen la obra, aparte de las notas y las fuentes presentadas, en forma exhaustiva, debe agregarse la Relación de la obra de Francisco Bernis, catálogo completísimo, minucioso hasta la exageración, si en la ciencia cabe mencionar esto, que va a resultar de muy difícil superación.

El contenido de la aportación de la profesora Pérez de Armiñán es, en realidad, una biografía y un estudio de la obra periodística de Luis Olariaga. La autora ha tenido la especial ventaja de que su madre, Carmen García Fresca, era sobrina de Olariaga. Como éste no tenía hijos, vivió en calidad de tal en su hogar. Por tanto, ha pasado a disponer del archivo familiar, esencial para este trabajo, de quien para ella era, en realidad, su abuelo.

Olariaga precisaba de esta primera indagación por su actividad ciertamente polifacética. Por una parte, era catedrático de Política Social y Legislación Comparada del Trabajo en el Doctorado de la Facultad de Derecho de la Universidad Central. Por otra, fue un importante investigador en cuestiones de la teoría del dinero. Ahí efectuó una importante tarea, tanto en lo que respecta al estar al día como escudriñando los entresijos de la realidad 
financiera española. Finalmente, fue un divulgador de los problemas económicos a través de la prensa. También tuvo proclividades literarias. Carmen Pérez de Armiñán me ha hablado de un cajón de comedias de su abuelo.

La tesis acota la investigación al período 1915-28, y a su perspectiva periodística divulgadora tras una indagación biográfica. Proporciona también un importante acervo bibliográfico.

La aportación de Sánchez Hormigo sobre Valentín Andrés Alvarez importa, a mi juicio, en tanto en cuanto ofrece un panorama bien trabado del doble aspecto - de economista y de literato- de este profesor asturiano. Los detalles se buscan hasta, se podría decir, el miniaturismo. Por una parte, recopila casi todo lo que se ha publicado sobre este profesor, desde enfoques muy diversos además.

La obra se estructura en cinco partes. La primera es un excelente y muy detenido Apunte biográfico; la segunda, una indagación sobre las aportaciones económicas de Valentín Andrés Alvarez, subdividido en tres grandes apartados: primero, sobre trabajos acerca del comercio exterior de España. El segundo bloque de aportaciones se relaciona con los estudios sobre Morfologia y análisis de mercado. Se aclara por Sánchez Hormigo muy bien la referencia de Stackelberg en sus Principios de Teoria Económica (Instituto de Estudios Políticos, Madrid, 1946, p. 244) a un trabajo inédito de Valentín Andrés Alvarez sobre análisis de mercados, y que, según el profesor alemán, «le iluminó mucho para la redacción del capítulo sexto de su obra». La tercera aportación de Valentín Andrés Alvarez es la que se refiere a sus trabajos en relación con el mundo de las relaciones intersectoriales.

El tercer gran apartado se refiere a los aspectos básicos del pensamiento de Valentín Andrés Alvarez. Comienzan con el planteamiento del raciovitalismo y perspectivismo - la doctrina del punto de vista-, de tan conocido origen en Ortega y Gasset. Sigue a esto un amplio despliegue del pensamiento liberal de este autor.

Otras dos aportaciones efectúa Sánchez Hormigo sobre el pensamiento de Valentín Andrés Alvarez. La primera, acerca de sus posturas básicas sobre el juego del hombre ante lo que ofrece la naturaleza. La segunda es su actitud ante la batalla del método, con una serie de matizaciones que habían pasado inadvertidas para todos los comentaristas de la obra de Valentín Andrés Alvarez, quien zanja la cuestión así: «La política es la que moldea a través del orden jurídico, la realidad cambiante de la historia; pero una vez establecido un orden jurídico-económico, régimen de propiedad, de contratación, etc., el organismo económico funcionará según sus leyes propias e inevitables.»

Me interesa como colofón señalar que estos tres estudios, como el anterior en el tiempo verificado por el profesor Espínola sobre Perpiñá Grau en tesis doctoral que también dirigí, o el que yo he preparado sobre Fernández Baños 
para el volumen que dedicará el Banco de España como homenaje a Sardá, constituyen mi más reciente participación, directa, o a través de brillantes discípulos, en el conocimiento de la historia del pensamiento económico español del siglo $\mathrm{xx}$. 